\title{
Chapter 6 \\ Internet and Social Media Use \\ of Undocumented Migrants
}

\subsection{Introduction}

The internet and social media have become crucial tools for undocumented migrants and asylum seekers during their asylum-related journeys (Dekker and Engbersen 2014; Frouws et al. 2016; Merisalo and Jauhiainen 2020a). They have also become an essential part of their lives: 'I would never have been able to arrive at my destination without my smartphone ... I get stressed out when the battery even starts to get low' (Brunwasser 2015). As international academic literature demonstrated-even though it does not yet provide a clear picture of 'how the use of ICTs [Information and Communication Technologies] exactly impacts the way that migration works' (Zijlstra and van Liempt 2017: 175) — the majority of migrants use communication devices, as well as the internet and social media (Dekker et al. 2016; Merisalo and Jauhiainen 2020a, b), to connect themselves in various ways to Europe (Borkert et al. 2018). Many use them in the country of origin to prepare and plan their journeys. The use becomes more common during their journeys, when they become more stable in transit countries, or in the first country of their arrival, both in refugee camps and outside them. There the initial digital divides, and the differences in usage between asylum seekers with different backgrounds, decrease or even vanish (Merisalo and Jauhiainen 2020a, b). Finally, in the destination country, use of the internet and social media becomes even more common (Jauhiainen et al. 2019; Merisalo 2017).

Undocumented migrants can use various means to receive and exchange information and maintain social networks with family and friends. Among these are faceto-face meetings (direct communication with peers or relatives who have already moved to Finland); phone calls (international phone calls with family and friends); and the internet and social media (again, for keeping in touch with family and friends, sharing pictures, news, and updates; or finding a job, food, clothing, or shelter for the night). One risk the scholars have highlighted regarding the wide use of mobile devices by undocumented migrants is surveillance by the state, 
particularly by the police (see, for instance, Borkert et al. 2018; Gillespie et al. 2016, 2018; Wall et al. 2017).

In Finland, the majority of asylum seekers seek online information about the asylum process, job opportunities, places to live, and their rights. Almost eight out of ten asylum seekers consider social media to be an important tool for building and maintaining their social relationships in Finland (Merisalo 2017). As previously stated, the majority of undocumented migrants with whom we conducted the research were former asylum seekers who failed the asylum process in Finland; however, communication devices, the internet, and social media remained essential tools, even after the migrants' change of legal status: 'Digital spaces have become vital for people to relate to family and friends, receive information about the new society they live in and pass time' (Witteborn 2014: 74).

In Sect. 6.2, we study the digital divides of asylum seekers and undocumented migrants: their access to the internet and social media applications, their ability to use them, and the impact of their use. Although asylum-related journeys were very challenging for most of the asylum seekers, use of the internet and social media became more widely practiced among the total population of asylum-related migrants. In Sect. 6.3, we discuss the details of the use of the internet and social media among undocumented migrants in Finland. Having gained the knowledge, skills, and opportunities to use these tools, the transition from asylum seeker to undocumented migrant did not substantially change their usage. These were very important tools for developing and maintaining social networks and searching for, and receiving, relevant information. In Sect. 6.4, we turn our attention to the rumours, as well as perceived and normative misinformation, that often spread rapidly through the social media undocumented migrants use (Ruokolainen and Widén 2020; Tedeschi and Gadd 2021). Rumours and misinformation are always part of social media in general, but we indicate what particularities exist in social media for undocumented migrants. In Sect. 6.5, we present the conclusions and also make suggestions regarding the usage of the internet and social media by undocumented migrants.

\subsection{Digital Divide}

In general, three digital divides exist in the population. The first-level divide concerns access to the internet; that is, whether people have or do not have access to the internet and related devices (Hargittai and Hinnant 2008; Schreeder et al. 2017). In the contemporary world, the first-level digital divide often relates to which of the undocumented migrants have mobile phones with inexpensive internet access or easy access to wi-fi.

The second-level digital divide involves people's ability to use the devices to gain access to the internet, connect to social media, and use these in ways that are useful to them (i.e. having sufficient related resources and skills; Schreeder et al. 2017). For an undocumented migrant, the second-level digital divide concerns, for example, 
Table 6.1 Internet use by undocumented migrants (\%)

\begin{tabular}{l|l|l|l|l|l}
\hline & $\begin{array}{l}\text { Every } \\
\text { day }\end{array}$ & $\begin{array}{l}\text { Many times a } \\
\text { week }\end{array}$ & Weekly & $\begin{array}{l}\text { Less } \\
\text { frequently }\end{array}$ & Never \\
\hline In country of origin & 54 & 18 & 1 & 17 & 10 \\
\hline $\begin{array}{l}\text { During journey to } \\
\text { Finland }\end{array}$ & 34 & 23 & 10 & 21 & 12 \\
\hline In Finland & 85 & 10 & 2 & 2 & 1 \\
\hline
\end{tabular}

whether he/she is able to use social media to maintain contact with his/her family and friends or find information on the internet that supports his/her goals. Most undocumented migrants come from countries in which general use of the internet is less common than in the EU member states, including Finland; therefore, fewer members of the population in their countries of origin have learned how and when to use the internet.

The third-level digital divide relates to the impact of the internet, social media and, more broadly, digitalisation on the lives of the population (Schreeder et al. 2017); for example, how interactions in social media enhance the social lives of undocumented migrants or how information and misinformation (e.g., fake news and rumours) in social media affect their decisions and lead to improvement or non-improvement of their everyday lives.

We analysed the development of internet use among undocumented migrants and how the use developed in their countries of origin, during their journeys to Finland, and within Finland (see Table 6.1). In general, a larger number of migrants used the internet in Finland than in their countries of origin. Of the respondents, $10 \%$ had never used the internet in their countries of origin, $12 \%$ did not use it during their travels to Finland, and $1 \%$ did not use the internet at all. Compared to the total adult population of Finland, a larger proportion of the undocumented migrants (the survey respondents) used the internet (International Telecommunications Union 2019); however, the majority of respondents $(96 \%)$ were younger than 50 years old and thus younger than the adult population of Finland. In general, the older population (older than 60 years old) used the internet substantially less frequently than the younger one (Barbosa Neves et al. 2018).

Three out of four respondents (73\%) were at least weekly users of the internet in their countries of origin, slightly more (77\%) during their travels to Finland, and almost all (96\%) within Finland. Of the Iraqi men, six out of seven (87\%) used the internet during their journeys to Finland. This suggested that they were communicating and searching for information on the internet during their travels, but not necessarily receiving accurate information about Finland (see also Tedeschi and Gadd 2021). Very frequent users (i.e. those who used the internet daily) in their countries of origin constituted a little over half (54\%) of respondents, substantially fewer (34\%) used it during their trips to Finland, and many more (85\%) in Finland. These results indicated that almost all became internet users between the beginning of their asylum-related journeys and achieving a measure of stability in their destination country; however, fewer undocumented migrants had the opportunity 
to use the internet daily during their actual journeys, or simply chose not to use it daily.

Those undocumented migrants who were the most frequent internet users in Finland were, in general, employed men from urban backgrounds who had made friends in Finland. Almost all of the frequent internet users (97\%) had internet access via their mobile phones; by contrast, those who used the internet less than weekly in Finland were unemployed and from rural backgrounds, a third (33\%) of whom had internet access via their mobile phones (while 67\% did not know about it).

\subsection{Internet and Social Media Usage among Undocumented Migrants}

Social media had different impacts on undocumented migrants in different phases of their journeys to Finland. About one out of three respondents (35\%) claimed that information and/or interaction through social media affected their decisions to come to Finland ( $21 \%$ did not know; $44 \%$ disagreed). For those who did not use the internet and social media, social media had less impact; in fact, of those who were active users of the internet (at least a few times per week) in their countries of origin and during their journeys to Finland, two out of five (41\%) claimed that information and/or interaction on social media affected their decisions to come to Finland (16\% did not know; $43 \%$ disagreed). In general, social media was a supportive tool that influenced the mobility decisions of the asylum-related migrants (Merisalo and Jauhiainen 2020b).

As we illustrated in Sect. 6.2, use of the internet has become common among undocumented migrants in Finland. Besides the internet, many of them also use social media. Three out of four respondents who used the internet (73\%) were also users of social media. The most common applications they used were WhatsApp (55\%) and Facebook (51\%); however, they also used other social media applications, such as Viber (21\%) and Skype (9\%). The use of e-mail was less common (12\%). There were some differences between the users of Facebook and WhatsApp. The Facebook users were primarily those who came to Finland in 2016 or later and who were younger (less than 30 years old); by contrast, the WhatsApp users were from all age groups. Such differences have been found to exist, in general, among asylum-related migrants (Merisalo and Jauhiainen 2020b).

Of those respondents who used the internet in Finland, six out of seven (85\%) believed that use of the internet, social media, or mobile applications made their lives easier in Finland (8\% did not know; 7\% were not of that opinion). Those internet users who did not think that the use of the internet, social media, or mobile applications made their lives easier in Finland were usually more than 30 years old, with lower education levels, and had been in Finland for several years (i.e. they came to Finland in 2015 or earlier). 
ICTs also play a crucial role in the formation of transnational networks (Oiarzabal and Reips 2012). They facilitate the networking of families that are scattered around the world (Madianou 2014). ICTs thus, at the same time, help (though only to a certain extent) individuals to manage their loneliness, the obstacles that their migration journeys (including to their destination countries) often pose, and the lack of information and knowledge available through official channels (such as official websites, the online immigration pages of central and local governments, etc.):

Information communication technologies (ICTs) are supporting the transformation of family networks into transnational ones, with potentially significant consequences in the psychology of immigration and family mental health. Social technologies may be influencing and mainstreaming the transnational experiences while families are finding resilient ways to confront the difficulties posed by immigration (Bacigalupe and Cámara 2012: 1425).

Undocumented migrants use the internet, social media, and mobile applications for various purposes, as do regular residents in Finland. One important purpose is to maintain and develop strong and weak ties, whereby 'the strength of a tie is a (probably linear) combination of the amount of time, the emotional intensity, the intimacy (mutual confiding), and the reciprocal services which characterise the tie' (Granovetter 1973: 1361). As discussed in Sect. 4.5, for example undocumented migrants use the internet and social media to keep in contact with family. ICTs facilitate communication across national borders and are crucial for the migrants' transnational experiences (see Tedeschi et al. 2020), including those of undocumented migrants. Four out of five respondents (80\%) kept in contact with their families and/or friends in their countries of origin, and all (100\%) used social media for this purpose. Of those who kept in contact with their families and/or friends in their countries of origin, every respondent used either WhatsApp (53\%) or Facebook $(51 \%)$. Of those who were in daily contact with friends and/or family, many $(45 \%)$ made phone calls, but also used social media (40\%), Skype (12\%), or SMS (10\%). In addition, of the respondents who made friends during their journeys before coming to Finland and kept in touch with these friends, most (58\%) used social media to maintain contact, but many (40\%) also used phone calls. Speaking to one's parents (by phone, Skype, or other devices) can be very important, as one undocumented migrant told us:

\footnotetext{
I need to talk with my parents on the phone every day. They are in Austria, and I am alone here. I am so worried that, since I am not with them, something might suddenly happen to them and I might lose them, so the first thing I do in the morning is call them.
}

Dekker and Engbersen (2014) highlighted that the use of communication devices in general, and of the internet and social media in particular, helps migrants to maintain strong ties with family and friends and develop weaker ties that might support their journeys and their survival in the destination countries. Migrants' need to maintain and develop these strong and weak ties during their fragmented journeys increases their use of social media (Merisalo and Jauhiainen 2020b). These tools build a new, dynamic infrastructure made of ties (people and also services) that influence and shape the migrants' everyday lives. They also provide unofficial 
information and knowledge that sometimes turns out to be vital and essential for asylum-related migrants, such as finding employment.

As discussed previously, communication devices, the internet, and social media are extremely important for maintaining and supporting contact with family members, as well as with close friends. In particular, those who came to Finland alone often highlighted the need to keep in touch with their families. During the qualitative ethnographic fieldwork, after a measure of trust was built, the first things they liked to show us were pictures, stored in their phones, of their families back in their home countries. Pictures of nephews and nieces, parents, brothers, sisters, and relatives in general were very common and often used as background images on their mobile phones. These contacts constituted strong ties for undocumented migrants who were living in very unstable conditions involving precarious and unsettled ties; therefore, being in touch with family was, for them, an element of stability in a life characterised by uncertainties, difficulties in making ends meet, loneliness, and rejection. 'Do you see how beautiful my little sister is? She is growing up very fast, and they send me her pictures via WhatsApp. I am so proud of her and my family, do you see? They are all so beautiful, and I miss them so much', said one undocumented migrant who was very stressed about his situation (his illegal status in the country), but for whom the family represented stability and an 'island of happiness' to carefully preserve and cherish.

As mentioned, the internet and social media were also important for forming and maintaining the weak ties that played important roles in their everyday lives. Referring to an online game he played every day, an undocumented migrant said:

\footnotetext{
You know, there is this new online game. It is very good, because I keep getting new friends through it. They come from all over the world, and I really like it, especially as I can also talk with them, not only chat. I get to speak in English, which is good. I also get to know other languages, so I have real conversations with people. Here [in Finland] I cannot talk with local people. I am very shy, and I also have the impression that they don't want me to talk with them.
}

This person seemed to have great difficulty making friends in the new environment of Finland, but could more easily do so in the digital world. These 'online friends' could be considered weak ties, but they constituted an important element of his wellbeing. He needed and wanted to build relationships, but apparently could not. The digital environment helped him compensate for what he could not find in the physical 'rejecting' space. Weak ties in unofficial networks, built casually through social media or through word-of-mouth in the migrants' own ethnic groups, can also open up possibilities of finding shelter for the night, food, clothing, and jobs (as the case of an undocumented migrant confectioner indicates):

When I arrived here I started selling my own sweets on Facebook (as I am a confectioner).

This is how my current boss found me, there: he said that he was looking for someone exactly like me and offered me a job in his shop, which I accepted.

Roughly three out of five respondents used the internet for clearly functional purposes, which the respondents indicated from multiple choice responses: searching for information about work opportunities in Finland $(58 \%$ of all 
Table 6.2 Undocumented migrants' searches for information on the internet (\%)

\begin{tabular}{l|l|l|l}
\hline & Yes & No & Don't know \\
\hline Finnish localities in which to possibly live in the future & 62 & 30 & 8 \\
\hline Current locality of residence in Finland & 62 & 32 & 5 \\
\hline Current situation in the former country of origin & 61 & 38 & 1 \\
\hline Rights in Finland & 59 & 32 & 9 \\
\hline Work opportunities in Finland & 58 & 31 & 11 \\
\hline
\end{tabular}

respondents), their rights in Finland (59\%), or the locality in which they were currently staying (62\%; Table 6.2). Those who were actively seeking such functional information from the internet were more often young adult females (18-29 years old) and those who arrived in Finland before 2016 (i.e. many Iraqi men). Those who rarely used the internet for above-mentioned functional purposes were often underage, unemployed, or had been in Finland for less than 3 years.

During the ethnographic study period, seeing them sitting alone and doing something with their mobile phones (talking, playing, chatting, listening to music, watching videos on YouTube, trying to learn the Finnish or English language with learning applications) for a long time (easily hours) was a very common occurrence: nowadays, 'stories, photographs, and videos are exchanged in online social networks on an ever larger scale' (Dekker et al. 2016: 539).

In fact, mobile applications can also be used for functional purposes, such as learning and practicing a language. Using mobile applications for learning and practicing a language signifies technical skills and motivation. Three out of five respondents $(61 \%)$ used mobile applications to practice the local Finnish language (39\% did not use mobile applications for this). Of those, one out of $12(8 \%)$ knew Finnish well, (almost one out of three (29\%) moderately, the majority (57\%) little, and a few (6\%) none at all). Learning the Finnish language with mobile applications applied to undocumented migrants with all levels of proficiency in Finnish. Of those who were using mobile applications to practice Finnish, almost all (92\%) wished to stay in Finland, and the majority (57\%) expected to be in Finland after 3 years (i.e. in 2021). Those who were using mobile applications to practice Finnish were often employed and had been in Finland for several years. Almost the same number of respondents (58\%) used mobile applications to practice English (42\% did not use mobile applications for this).

Use of the internet also related to potential migration inside Finland. Three out of five respondents $(61 \%)$ who used the internet sought information about localities in Finland in which they could live in the future; however, fewer respondents $(33 \%)$ were of the opinion that information and/or interaction on social media affected their decisions about where to live in Finland (45\% disagreed; 22\% did not know).

We also asked, specifically, whether the respondents actively followed events in their countries of origin. The majority (61\%) continued to follow events (1\% did not know; 38\% did not follow them); therefore, the internet facilitated ongoing contact with their countries of origin, even without strong ties to family and friends. Those who did not follow events in their former countries were often undocumented 
migrant women who had family with them in Finland and/or those with lower education levels. In general, very few wanted to return to their countries of origin. Slightly more (9\%) of those who followed events in their countries of origin wanted to return to those countries compared with those who did not follow them (7\%). When undocumented migrants, for various reasons, wanted to weaken or cut ties with their families or their countries of origin (see Sect. 4.5), the massive use and widespread presence of social media made cutting the ties difficult. In fact, a presence in social media has the drawback of deepening their existing traumas, unwanted connections, and bad memories.

\subsection{Facts and Rumours on the Internet and in Social Media Affecting Undocumented Migrants}

As indicated in Sect. 6.1, undocumented migrants and asylum seekers come across different types of information and misinformation on the internet and in social media. Some information seems truthful, but turns out to be misinformation because it is inadequate, presented inadequately, or outdated. Purposeful misinformation leads to false hopes or unrealistic expectations. There are also many kinds of distorted information and rumours. Undocumented migrants' different social, cultural, and historical aspects, situations, and contexts are involved in determining whether they perceive information as accurate information, misinformation, or disinformation. Misinformation can be defined as inaccurate, incomplete, vague, or ambiguous information, depending on the specific context or situation. Due to their vulnerable and marginalised situations, undocumented migrants may perceive information differently from the majority of the population (Ruokolainen and Widén 2020).

In Finland, the authorities use both 'analogue' and 'digital' channels to maintain contact with undocumented migrants; for example, the city of Helsinki effectively introduced one-to-one official mobile communication, with text messages to undocumented migrants regarding decisions about their social service requests. Upon receipt of an SMS notification of a decision, a migrant could go to the municipality offices and collect, in the case of a positive decision, his/her voucher to buy food in supermarkets and his/her public transportation travel card.

Sometimes such information is spread only through 'analogue' methods for security reasons. In one large town (Turku), a leaflet listing places where undocumented migrants could go for help after the termination of reception centre services was physically and directly handed to them in the centres. It was not available on the internet-at least not when this research was carried out. In this case, NGOs (e.g. Red Cross volunteers) distributed the leaflets to the reception centres in the Turku area. Indeed, the places where they could go to get help could be considered 'sensitive', and the decision to not publicise the locations on the internet was made to protect the migrants from 'unwanted visits'; for example, by far-right extremists. 
The necessity of making the locations visible on the internet (recognised by the volunteers, considering that many undocumented migrants are very afraid of going to public places to seek information) needed to be carefully balanced against the security and safety of these vulnerable people.

Despite social and community workers from municipalities and NGOs being the official people on whom to rely, undocumented migrants often turned to unofficial social media channels and networks to survive in everyday life in Finland, such as by finding a job, accommodation, food, or clothes. This is what Williams and Baláž (2012: 178) called 'lack of trust in expert advice and reliance on alternative knowledge sources'. Unofficial, rather than official, information and knowledge on the internet is often more widespread and 'effective' for undocumented migrants.

Indeed, official information on official internet channels was often not clear enough to be comprehended by undocumented migrants, considering the language barriers, to name but one factor. The purposeful information thus turned into perceived misinformation due to the specific contexts of undocumented migrants, illustrating the extent to which perceptions of information are social (see Ruokolainen and Widén 2020). In this respect, we very soon recognised a disparity in the former asylum seekers' understanding of the asylum process. The lack of accessibility and clarity of official information on the internet about the asylum procedure and the status of undocumented migrants obliged many turn to unofficial channels that provided incorrect information or even purposeful misinformationbecause it was easier to absorb than the information conveyed through the official websites.

The use of ICT devices and, in general, the information shared among their own networks (such as family and friends), whatever the chosen medium, thus had two facets. As indicated in Sect. 6.3, the positive aspect enabled undocumented migrants to keep in touch with their families and friends; build weak relationships with online friends while temporarily relieving stress; and find information about where and how to find a job, food, or shelter for the night.

There were also negative aspects regarding safety and security: the surveillance of undocumented migrants' ICT use by the authorities, and cases in which rumours and false or criminalising information spread on the internet might negatively influence their actions. If, for example, they wanted to make a new asylum application, they might decide to marry or change their religion or sexuality, because this specific misinformation was widespread on social media as a viable option to easily get asylum. However, such information is usually fake, since Migri thoroughly assesses each application and its reliability.

Yet another critical aspect of the internet and social media concerns online news and its (often negative) impact on both society and undocumented migrants; for instance, dissemination in social media of the news that '20-34-year-old people from Iraq were found to have committed 10 times more sexual offenses of some kind in 2017 than Finnish citizens of the same age' (Yle.fi 2019) made undocumented migrants, especially young Iraqi adults (who constitute the majority of undocumented migrants in Finland) or people who looked similar, go even further into hiding, due to a perceived increase of intolerance towards them (MacDonald 2017). 
In our survey, we asked the undocumented migrants whether they had received misinformation about Finland through social media. Almost two out of five respondents (37\%) answered that they had received misinformation about Finland through social media (as did many of those who actively used the internet), 15\% did not know, and $48 \%$ said that they had not. We also asked if they had received misinformation about Finland from somewhere other than social media. One out of three respondents (34\%) answered that they had received misinformation about Finland, $18 \%$ did not know, and half (48\%) claimed that they had not. In total, over two out of five respondents (44\%) had, and 56\% had not, received misinformation about Finland. Those who had received misinformation about Finland were most often underage respondents, those with low education levels, and more often men than women.

Even though, as Carling and Sagmo (2015) maintained, 'the literatures on migration and on rumour remain largely separate,' still 'rumours are powerful and widespread elements in the dynamics of migration'. From our empirical work, it soon became apparent how many of the undocumented people we met followed and believed in rumours spread through their own networks, among their contacts, as well as in social media:

I found this information in some Facebook groups ... that Finland is in first place for human rights ... This is why I am here.

I wanted to go as far as possible from my country. I wanted something completely different, and I was looking for a safe place. Finland was exactly that place to me. This is what I was told, and found in social media. I also found that I wouldn't meet many of my peers in Finland, but reality was very different from what I had expected.

This is what Wall et al. (2017: 240) called information precarity, which risks leaving people 'vulnerable to misinformation [and] stereotyping'. It cannot be said that information spread on the internet and in social media was the reason why they actually moved to Finland, but, along with comments from their 'trusted' networks (which were often used to double-check the truthfulness of information coming from unknown sources; see Dekker et al. 2018), and new rumours and information collected and accumulated during their journeys to and within Europe, it played an important role in their decisions to move and in their final choice of the destination country, as the previous quotations show.

Another undocumented migrant revealed one day that he had relatives already living in Finland, and, when he called them, they suggested that he follow them, because 'it is so very easy to get asylum here, and then a job, and a place to stay' (Tedeschi and Gadd 2021). They shared their experience with him, and it was, to a certain extent, what he wanted to hear, confirming what was already in his mind (Burt 2001); however, it turned out to be untrue, as another research participant also clearly highlighted (see the second previous quotation): ultimately, reality was very different from what he expected and what he was told. This can often happen when, to some extent, the source of information is 'trusted' (as in the case of the relatives living in Finland). This is what Borkert et al. (2018) called 'learning by experience', when refugees told the researchers how they 'became aware of when to distrust information only when facing different reality'. 
Not only do rumours and unofficial information and knowledge affect the decisions of people to migrate and, in some cases, to choose Finland as the destination country, but, both upon arrival and through subsequent asylum applications, they also affect the people's approaches to their asylum applications (Tedeschi and Gadd 2021), as mentioned previously. This cannot be overlooked, specifically when considering cases of undocumented migrants who are ex-asylum seekers, as we do in this book. Via Facebook, through social media, they share stories and recommendations as to how to get asylum in Finland. These stories and unofficial recommendations might be more or less trustworthy, but asylum seekers and ex-asylum seekers tend to follow them, often ending up undocumented.

Let us, for instance, consider subsequent asylum applications. As Migri (2018) reported, and we already showed in Chap. 3, 'at the moment about every second asylum application is a subsequent application' and in 2020 they were two out of three applications. For Migri to process a subsequent application, new grounds (i.e. new information) must be provided by the asylum seeker, otherwise, Migri will drop the case without looking into it. Undocumented migrants, following the misinformation spread in social media channels and/or through the migrants' own more or less close networks, started subsequent applications where the new grounds were a change of religion, gender, or sexuality or new documents (false and sometimes sold online), with the purpose of 'demonstrating' that they were under threat in their home countries. There were cases with 'genuine' new grounds (some obtained new valid and reliable information from their countries of origin) but, in other cases, the new information was presented on purpose to legalise their stay in the country. Such information in social media channels is usually untrue. As previously stated, Migri often unmasks untrue intentions and denies asylum. The drawback, however, is that, due to the increase of these fake cases, there is always the risk that true, genuine grounds are not recognised and asylum is denied. Given the importance of this matter, both a clear stance from the competent institutions, revealing rumours and misinformation, and active engagement with the asylum seekers who ask for clarification from official sources, are now greatly needed.

The last critical point to mention relates to news, widespread online and especially in social media, of Iraqi asylum seekers or refugees committing sexual offences in Finland. Highlighting that this ethnic group committed the offences increased the general intolerance towards them. In Finland and elsewhere in Europe, 'immigration coverage [in the media] is often negative and conflict-centred. Frequent exposure to such media messages leads to negative attitudes towards migration [and] may activate stereotypical cognitions of migrant groups' (Eberl et al. 2018: 207)_even if the information might be trustworthy. Resulting from this media discussion, we noticed a clear difference in the behaviour of some undocumented migrants - especially the ones from Iraq. When they noticed increased intolerance towards them (Boomgaarden and Vliegenthart 2009), they went further into hiding, even to the extent of denying their real nationalities. As one young man, upset by the news, said: 
You know, now, because of this news that is everywhere on the internet and in social media, when I meet or speak with someone who is Finnish, I do not say that I am from Iraq anymore. I tried, but they then go away, they don't want to talk to me, because I am 'a bad guy from Iraq'- but I am not bad! I didn't do anything wrong. Therefore, I say that I am from Turkey. If I say like this, they then talk to me.

Information flows through migrants' own networks, or indirectly through the internet and social media, provide unofficial and official important and trustworthy information (i.e. how to get shelter for the night, food and clothing), but also untrustworthy gossip that can become dangerous (i.e. how to easily gain asylum in Finland). There are also (true or untrue) messages, widely spread on the internet, that have serious consequences because they stigmatise ethnic groups: 'The nature of these elements may stimulate an image of ethnic minorities as dangerous and threatening' (Jacobs 2017: 822). Undocumented migrants are greatly affected by misinformation and rumours, and modify their choices, decisions, and movements accordingly. It is very important to acknowledge how, where, and by whom information is transmitted, as well as the role it plays in the everyday lives of these people.

\subsection{Conclusions}

In this chapter, we have explored the usage and role of the internet and social media, as well as the facilitated information exchanges, in undocumented migrants' lives. In general, the digital divides among undocumented migrants narrowed during their journeys from their countries of origin to Finland. Most of them become acquainted with the internet and social media after leaving their countries of origin and, when residing in Finland, the first-level digital divide (access to the internet and social media) and the second-level one (ability and resources to use related devices) definitely narrowed. Not all differences in access, use, and impact disappeared. Moreover, some undocumented migrants — although very few-still did not engage with the internet and social media. Overall, the internet and social media were fundamental tools for undocumented migrants to keep in contact with their families and friends and to obtain various kinds of information.

On the other hand, undocumented migrants are becoming increasingly and similarly exposed to the third-level digital divide (impact of the internet and social media). Whatever the medium an undocumented migrant uses, information received through it can be either trustworthy or fake. Official information provided by authorities and local institutions sometimes remains obscure or is misunderstood, turning it into misinformation from the point of view of undocumented migrants. They may then become sceptical of the authorities, so that truthful information is perceived as misinformation that the migrants cannot rely on; therefore, undocumented migrants turn to their own networks (online or offline) to find the information they are seeking, as an easier way to solve their problems. When the information is unofficial, it runs the risk of being untrustworthy misinformation; for example, such 
misinformation influenced some migrants' behaviour even before their arrival in Finland. The widespread word-of-mouth claims that it is easy to obtain asylum in Finland, or that one can receive substantial financial support as an asylum seeker, both turned out to be fake. Another example is that, after receiving misinformation, some undocumented migrants in Finland submitted new asylum applications with false new grounds that led (again) to their rejection. This and more dangerous misinformation on the internet and social media needs to be studied and explored further. Such dangerous misinformation relates to illegal activities, attracting undocumented migrants into exploitative situations and jobs that pay very little, or nothing, hoping that they might obtain a work-based residence permit (which is often not the case, see Sect. 4.4).

Finally, communication media assume a very important role in the life of migrants, whatever their legal status. Widespread news on the internet and social media that criminalises specific ethnic groups (even if the criminalisation is based on real facts) may result in increased intolerance towards all members of those ethnic groups, or even towards all immigrants. This pushes undocumented migrants and many other migrants further into hiding, creating a shadow society that is separate from the official one.

\section{References}

Bacigalupe, G., \& Cámara, M. (2012). Transnational families and social technologies: Reassessing immigration psychology. Journal of Ethnic and Migration Studies, 38(9), 1425-1438.

Barbosa Neves, B., Fonseca, J., Amaro, F., \& Pasqualotti, A. (2018). Social capital and internet use in an age-comparative perspective with a focus on later life. PLoS One, 13(2), e0192119.

Boomgaarden, H., \& Vliegenthart, R. (2009). How news content influences anti-immigration attitudes: Germany, 1993-2005. European Journal of Political Research, 48(4), 516-542.

Borkert, M., Fisher, K., \& Yafi, E. (2018). The best, the worst, and the hardest to find: How people, mobiles, and social media connect migrants in(to) Europe. Social Media + Society, 4(1), 1-11.

Brunwasser, M. (2015). A 21st-century migrant's essentials: Food, shelter, smartphone. New York Times 26.5.2015. Available at: https://www.nytimes.com/2015/08/26/world/europe/a-21stcentury-migrants-checklist-water-shelter-smartphone.html. Accessed 6 May 2019.

Burt, R. (2001). Bandwidth and echo: Trust, information, and gossip in social networks. In A. Casella \& J. E. Rauch (Eds.), Networks and markets: Contributions from economics and sociology (pp. 30-74). New York: Russell Sage Foundation.

Carling, J., \& Sagmo, T. (2015, January 13-15). Rumour and migration. Paper presented at The Changing Face of Global Mobility. International Migration Institute, Oxford, UK.

Dekker, R., \& Engbersen, G. (2014). How social media transform migrant networks and facilitate migration. Global Networks, 14, 401-418.

Dekker, R., Engbersen, G., \& Faber, M. (2016). The use of online media in migration networks. Population, Space and Place, 22, 539-551.

Dekker, R., Engbersen, G., Klaver, J., \& Vonk, H. (2018). Smart refugees: How Syrian asylum migrants use social media information in migration decision-making. Social Media + Society, 4 (1), $1-11$.

Eberl, J., Meltzer, C., Heidenreich, T., Herrero, B., Theorin, N., Lind, F., Berganza, R., Boomgaarden, H., Schemer, C., \& Strömbäck, J. (2018). The European media discourse on 
immigration and its effects: A literature review. Annals of the International Communication Association, 42(3), 207-223.

Frouws, B., Phillips, M., Hassan, A., \& Twigt, M. (2016). Getting to Europe the Whatsapp way: The use of ICT in contemporary mixed migration flows to Europe. Regional Mixed Migration Secretariat Briefing Paper 2016.

Gillespie M., Ampofo L., Cheesman M., Faith B., Iliadou E., Issa A., \& Skleparis D. (2016). Mapping refugee media journeys. Smartphones and social media networks (Research report). Available at: http://www.open.ac.uk/ccig/sites/www.open.ac.uk.ccig/files/Mapping\%20Refu gee\%20Media\%20Journeys\%2016\%20May\%20FIN\%20MG_0.pdf. Accessed 8 May 2019.

Gillespie, M., Osseiran, S., \& Cheesman, M. (2018). Syrian refugees and the digital passage to Europe: Smartphone infrastructures and affordances. Social Media + Society, 4(1), 1-12.

Granovetter, M. (1973). The strength of weak ties. American Journal of Sociology, 78(6), $1360-1380$.

Hargittai, E., \& Hinnant, A. (2008). Digital inequality. Differences in young adults' use of the Internet. Communication Research, 35, 602-621.

International Telecommunications Union. (2019). Key ICT indicators for developed and developing countries and the world. ITU. https://www.itu.int/en/ITU-D/statistics. Accessed 15 Aug 2019.

Jacobs, L. (2017). Patterns of criminal threat in television news coverage of ethnic minorities in Flanders (2003-2013). Journal of Ethnic and Migration Studies, 43(5), 809-829.

Jauhiainen, J., Eichholz, L., \& Spellerberg, A. (2019). Refugees, asylum seekers and undocumented migrants in Germany, 2019. The case of the Rhineland-Palatinate and Kaiserslautern. Publications of the Department of Geography and Geology of the University of Turku 13.

MacDonald, F. (2017). Positioning young refugees in Australia: Media discourse and social exclusion. International Journal of Inclusive Education, 21(11), 1182-1195.

Madianou, M. (2014). Smartphones as polymedia. Journal of Computer-Mediated Communication, $19,667-680$.

Merisalo, M. (2017). Internet, sosiaalinen media ja mobiilisovellukset turvapaikanhakijoiden kotoutumisessa ja muuttopäätöksissä Suomessa. [In Finnish, Internet, social media and mobile phone applications in the integration and migration decisions of asylum seekers in Finland]. In J. Jauhiainen (Ed.), Turvapaikka Suomesta? Vuoden 2015 turvapaikanhakijat ja turvapaikkaprosessit Suomessa (Vol. 5, pp. 103-117). Turku: Publications of the Department of Geography and Geology of the University of Turku.

Merisalo, M., \& Jauhiainen, J. (2020a). Digital divides among the asylum-related migrants: Comparing the internet use and smartphone ownership. Tijdschrift voor Economische en Sociale Geografie, 111(5), 689-755.

Merisalo, M., \& Jauhiainen, J. (2020b). Asylum-related migrants' social media use, mobility decision and resilience. Journal of Immigrant \& Refugee Studies.

Migri. (2018). At the moment about every second asylum application is a subsequent application. Available at: https://migri.fi/en/article/-/asset_publisher/turvapaikkahakemuksista-noin-puoleton-talla-hetkella-uusintahakemuksia. Accessed 23 Mar 2019.

Oiarzabal, P., \& Reips, U. (2012). Migration and diaspora in the age of information and communication technologies. Journal of Ethnic and Migration Studies, 38(9), 1333-1338.

Ruokolainen, H., \& Widén, G. (2020). Conceptualising information in the context of asylum seekers. Information Processing and Management (Online first).

Schreeder, A., van Deursen, A., \& Dijk, V. (2017). Determinants of internet skills, uses and outcomes. A systematic review of the second- and third-level digital divide. Telematics and Informatics, 34, 1607-1624.

Tedeschi, M., \& Gadd, K. (2021). On multiple spacetimes in the everyday lives of irregular migrants in Finland. The Geographical Journal (online first).

Tedeschi, M., Jauhiainen, J., \& Vorobeva, E. (2020). Transnationalism: Current debates and new perspectives. GeoJournal (Online first).

Wall, M., Campbell, M., \& Janbek, D. (2017). Syrian refugees and information precarity. New Media \& Society, 19, 240-254. 
Williams, A., \& Baláž, V. (2012). Migration, risk, and uncertainty: Theoretical perspectives. Population, Space and Place, 18, 167-180.

Witteborn, S. (2014). Forced migrants, emotive practice and digital heterotopia. Crossings: Journal of Migration \& Culture, 5, 73-85.

Yle.fi. (2019). Tuesday's papers: Finland's sexual abuse statistics, human rights talk in China. Yle 15.1.2019. Available at: https://yle.fi/uutiset/osasto/news/tuesdays_papers_finlands_sexual_ abuse_statistics_human_rights_talk_in_china/10596457. Accessed 8 May 2019.

Zijlstra, J., \& van Liempt, I. (2017). Smart(phone) travelling: Understanding the use and impact of mobile technology on irregular migration journeys. International Journal Migration and Border Studies, 3(2/3), 174-191.

Open Access This chapter is licensed under the terms of the Creative Commons Attribution 4.0 International License (http://creativecommons.org/licenses/by/4.0/), which permits use, sharing, adaptation, distribution and reproduction in any medium or format, as long as you give appropriate credit to the original author(s) and the source, provide a link to the Creative Commons license and indicate if changes were made.

The images or other third party material in this chapter are included in the chapter's Creative Commons license, unless indicated otherwise in a credit line to the material. If material is not included in the chapter's Creative Commons license and your intended use is not permitted by statutory regulation or exceeds the permitted use, you will need to obtain permission directly from the copyright holder. 